half-minute, so as to ascertain the time to a second, a special arrangement, called a spring remontoire, has been added, by means of which the wheels of the clock are detained for thirty seconds and escape at the half-minute, allowing the weight to move the hands over half a minute's space, and wind up a small clock-spring in the spindle, which revolves in two minutes. This keeps the penclulum and the escapement going while the rest of the works are held back. The following is a technical description of this remontoire:- "The whell in the spindle, which revolves once in five minutes, drives a second pinion with eight leeth, the spindle of which projects through the back of the clock frame, and carries a little cylinder with two notches at the end, one broad and shallow, the other narrow and deep. At the end of the remontoire arms are two steel projections, one of which passes through the broad notch and the other through the narrow one. As the two-minute spindle revolves, with the notched cylinder, it brings a notch in a right position to let one of the arm projections through every half-minute, allowing the train to move the hands, and wind up the small spring. To effect this the pinion with sixteen leaves is loose on the two. minute spindle, and is only attached to one end of the spring. The clock is also supplied with Denison's double three-legged gravity escapement.

THE Mount Washington Railway, which ascends the White Mountains, New Hampshire, U.S., is about three miles in length, the average gradient being a little more than $I$ in 4 , which is increased in some places to the extraordinary extent of $x$ in 3 . The engine draws itself up the line by means of a "pinion," which works into a strong "rack" fixed between the rails, and the ascent of three miles is completed in about one hour.

M. MoHn, Director of the Observatory of Christiania, has recently surveyed the névé field of Fostedalsbroen, which occupies 750 square kilometres. He finds that it feeds twenty. two glaciers of the first order and more than 200 smaller ones. The nézé is seventy kilometres from the sea.

Messrs. Bell and Daldy have just issued the first part of a work bearing the title "Natural Phenomena and Chronology of the Seasons," and containing a chronological register of the remarkable frosts, droughts, thunderstorms, gales, floods, earthquakes, \&c. which have occurred in the British Isles since A.D. 220. The author, Mr. E. J. Lowe, F.R.S., the wellknown meteorologist, wishes it to be understood that his chief object in publishing what is confessedly a very imperfect record is to call attention to the subject, and elicit further information for a more extensive work, embracing the more remarkable natural phenomena of foreign countries. The compilation of a catalogue of this nature, if it is to be of any real benefit to science, involves an enormous amount of labour and much critical skill. The original authorities for the phenomena recorded should, in each case, be referred to so precisely that the quotations may be readily verified. It is hardly satisfactory to see the Preston Hercld quoted in support of the assertion that 1,500 houses were unroofed and destroyed in London, in the year 944 .

Mr. JoHn H. Martin, secretary to the Maidstone and Mid. Kent Natural History Society, has just brought out the first number of a new publication, "Microscopic Objects figured and described," containing 16 wood-cnts and short descriptions of vegetable objects, from the yeast-plant to the spiral-vascular tissue from garden rhubarb. The work is intended, when complete, to contain about 200 figures, all of them original, to be issued in monthly numbers. It is proposed to commence with the primary forms of vegetable life, and to proceed onwards through the tissues to the woody structures of the Exogens and Endogens, next descending to the Acrogens, and so passing to the extreme limits of yegetable life, as the Desmidix, \&c., thence to the lower forms of animal life, the Infusoria, and on through the Radiata to the Insects, which will be drawn and described in their various orders, and the minute organs figured separately.

THE Architect states that Lieutenant Cole, R.A., and three sappers, sent out by the Secretary of State for India to take casts of the Sanchi Tope, have arrived in Calcutta. For the benefit of those of our readers who have not had the privilege of seeing Mr. Fergusson's magnificent work "On Tree and Serpent Worship," we may mention that the Sanchi Tope, a monument of very high antiquity, is surrounded by walls and gateways covered with elaborate sculptured decorations of the greatest interest to the student of the early history of the human race.

THE Field of Saturday last contains some interesting notes on special agricultural training-schools in France, Germany, and Switzerland. At Rutte in the Canton of Berne, and at Santhoven in Bavaria, particular attention is given to the theory and practice of dairy operations, and the general treatment of cow stock. The school of Lezardeau, on the estate of Count Conédic, in the Department of Finisterre, offers special facilities for the study of draining and irrigation. In this school there is a technical library, a museum, a callection of meteorological instruments, a laboratory, and touls of all descriptions. The general course of study includes elementary mechanics, agricultural chemistry and botany, the pruning and grafting of fruit-rees, the making of roads, and other practical knowledge. At Görtz, in Austria, is a special institution for silkworm culture, supporting a journal exclusively devoted to that branch of industry. The Athenoum states that the Ottoman Government is giving its support to a project of M. Netter, of Constantinople, to found an agricultural school for Jews in Palestine.

We have been requested to notify that the following premiums have been placed at the disposal of the Council of the Society for the Encouragement of Arts, Manufactures, and Commerce, for the term of seven years, by $M$. Septimus Piesse:-I. A premium of $£ 5$, for one pound of Otto of Bergamot, of the value of $I 6 s$. or more in the London market, being the pro. duce of plants (Citrus bergamia) grown in Australia, New Zealand, Natal, any of the British West India Islands, or any other British Colony or Dependency. 2. A premium of $£ 5$, for one ounce of Otto of Roses, of the value of 20 . or more in the London market, being the produce of any variety of roses grown together in one plantation in Australia, New Zealand, Natal, any of the British West India Islands, or any other British Colony or Dependency. 3. A premium of $£$ Io, for a canister of Enflowered Butter or Fat, so scented with any kind or sort of flower, either by infusion or enfleurage, or by means of these processes jointly, of the weight of 3 lbs. or more, and of the value of $6 s$. per $1 \mathrm{~b}$. in London. The said butter or fat to be enflowered or infused with flowers grown for the purpose in Austraita, New Zealand, Natal, any of the British West India Islands, or any other British Colony or Dependency.

\section{ON HAZE AND DUST}

SOLAR light in passing through a dark room reveals its track by illuminating the dust floating in the air. "The sun," says Daniel Culverwell, "discovers atomes, though they be invisible by candle-light, and makes them dance naked in his beams."

In my researches on the decomposition of vapours by light, I was compelled to remove these " atomes" and this dust. It was essential that the space containing the vapours should embrace no visible thing; that no substance capable of scattering the light in the slightest sensible degree should, at the outset of an experiment, be found in the "experimental tube" traversed by the luminous beam.

For a long time I was troubled by the appearance there of floating dust, which, though invisible in diffuse daylight, was at 
once revealed by a powerfully condensed beam. Two tubes were once revealed by a pow the path of the dust : the one containing placel in succession in the path of the dust : the one containing fragments of glo marble wetted with a strong solution of caustic potash. To my astonishment it passed through both. The air of the Royal Institution, sent through these tubes at a rate sufficiently slow to dry it and to remove its carbonic acid, carried into the experimental tube a considerable amount of mechanically-suspended matter, which was illuminated when the beam passed through the tube. The effect was substantially the same when the air was permitted to bubble through the liquid acid and through the solution of potash.

Thus, on the 5th of October, I868, successive charges of air were admitted through the potash and sulphuric acid into the exhausted experimental tube. Prior to the admission of the air the tube was optically entpty; it contained nothing competent to scatter the light. After the air had entered the tube, the conical track of the electric beam was in all.cases clearly revealed. This indeed was a daily observation at the time to which $I$ now refer:

$I$ tried to intercept this floating matter in various ways; and on the day just mentioned, prior to sending the air through the drying apparatus, I carefully permitted it to pass over the tip of a spirit-lamp flame. The floating matter no longer appeared, having been burnt up by the flame. It was therefore organic matrer. When the air was sent too rapidly through the flame, a fine blue cloud was found in the experimental tube. This was the smoke of the organic particles. I was by no means prepared for this result; for I had thought, with the rest of the world, that the dust of our air was, in great part, inorganic and noncombustible.

Mr. Valentin had the kindness to procure for me a small gasfurnace, containing a platinum tube, which could be heated to vivid redness. The tube also contained a roll of platinum gauze, which, while it permitted the air to pass through it, ensured the practical contact of the dust with the incandescent metal. The air of the laboratory was permitted to enter the experimental tube, sometimes through the cold, and sometimes through the heated tube of platinum. The rapidity of admission was also varied. In the first column of the following table the quantity of air operated on is expressed by the number of inches which the mercury gauge of the air-pump sank when the air entered. In the second column the condition of the platinum tube is mentioned, and in the third the state of the air which entered the experimental tube.

Quantity of Air. State of Platinum Tube. State of Experimental Tube.

\begin{tabular}{|c|c|c|c|c|}
\hline & & & & \\
\hline 15 inches & . & Cold & & Full of particles. \\
\hline " & - & - Red-hot & & Optically empty. \\
\hline 3 & - & - Cold & - & Futically empty. \\
\hline " & : & Cold. & & Full of particles. \\
\hline " & . & Red-hot & - & Optically empty. \\
\hline
\end{tabular}

The phrase "optically empty" shows that when the conditions of perfect combustion were present, the floating matter totally disappeared. It was wholly burnt up, leaving not a trace of residue. From spectrum analysis, however, we know that soda floats in the air; these organic dust particles are, I believe, the rafts that support it, and when they are removed it sinks and vanishes.

When the passage of the air was so rapid as to render imperfect the combustion of the floating matter, instead of optical emptiness a fine blue cloud made its appearance in the experinental tube. The following series of results illustrate this point :-

$$
\begin{aligned}
& \text { Quantity. } \\
& 15 \text { inches, slow } \text {. Platinum Tube. } \\
& 15 \text { Cold :" Red-hot: }
\end{aligned}
$$

Experimental Tube. Full of particles. Optically empty.

15 ", quick: Red-hot: : A blue cloud.

15 ", ", . Intensely hot: A fine blue cloud.

The optical character of these clouds was totally different from that of the dust which produced them. At right angles to the illuninating beam they discharged perfectly polarised light. The cloud could be utterly quenched by a transparent Nicol's prism, and the tube containing it reduced to optical emptiness.

The particles floating in the air of London being thits proved to be organic, I sought to burn them up at the focus of a concave reflector. One of the powerfully convergent mirrors employed in my experiments on combustion by dark rays was here made use of, but I failed in the attempt. Doubtless the floating particles are in part transparent to radiant heat, and are so far incom- bustible by such heat. Their rapid motion through the focus also aids their escape. They do not linger there sufficiently long to be consumed. A flame it was evident would burn them up, but I thonght the presence of the flame rould mask its own action among the particles.

In a cylindrical bean, which powerfully illuminated the dust of the laboratory, was placed an ignited spirit-lamp. Mingling with the flame, and round its rim, were seen wreaths of darkness resembling an intensely black smoke. On lowering the flame below the beam the same dark masses stormed upwards. They were at times blacker than the blackest smoke that 1 have ever seen issuing from the funnel of a steamer, and their resemblance to smoke was so perfect as to lead the most practised observer to conclnde that the apparently pure flame of the alcohol lamp required but a beam of sufficient intensity to reveal its clouds of liberated carbon.

But is the blackness smoke? The question presented itself in a moment. A red-hot poker was placed underneath the beam, and from it the black wreaths also ascended. A large hydrogen flame was next employed, and it produced those whirling masses of darkness far more copiously than either the spirit. flame or poker. Smoke was therefore out of the question.

What then, was the blackness? It was simply that of stellar space; that is to say, blackness resulting from the absence from the track of the beam of all matter competent to scatter its light. When the flame was placed below the beam the floating matter was destroyed in situ; and the air, freed from this matter, rose into the beam, jostled aside the illuminated particles, and substituted for their light the darkness due to its own perfect transparency. Nothing could more forcibly illus. trate the invisibility of the agent which renders all things visible. The beam crossed, unseen, the black chasm formed by the transparent air, while at both sides of the gap the thickstrewn particles shone out like a luminous solid under the powerful illumination.

But here a difficulty meets us. It is not necessary to burn the particles to produce a stream of darkness. Without actual combustion, currents may be generated which shall exclude the floating matter, and therefore appear dark amid the surrounding brightness. I noticed this effect first on placing a red-hot copper ball below the beam, and permitting it to remain there until its temperature had fallen below that of boiling water. The dark currents, though much enfeebled, were still produced. They may also be produced by a flask filled with hot water.

To study this effect a platinum wire was stretched across the beam, the two ends of the wire being connected with the two poles of a voltaic battery. To regulate the strength of the current a rheostat was placed in the circuit. Beginning with a feeble current the temperature of the wire was gradually augmented, but before it reached the heat of ignition, a flat stream of air rose from it, which when looked at edgeways appeared darker and sharper than one of the blackest lines of Fraunhofer in the solar spectrum. Right and left of this dark vertical band the floating matter rose upwards, bounding definitely the non-luminous stream of air. What is the explanation? Sinply this. The hot wire rarefied the air in contact with it, but it did not equally lighten the floating matter. The convection current of pure air therefore passed upwards among the particles, dragging them after it right and left, but forming between them an impassable black partition. In this way we render an account of the dark currents produced by bodies at a temperature below that of combustion.

Oxygen, hydrogen, nitrogen, carbonic acid, so prepared as to exclude all floating particles, produce the darkness when poured or blown into the beam. Coal-gas does the same. An ordinary glass shade placed in the air with its mouth downwards permits the track of the beam to be seen crossing it. Let coal-gas or hydrogen enter the shade by a tube reaching to its top, the gas gradually fills the shade from the top downwards. As soon as it occupies the space crossed by the beam, the luminous track is instantly abolished. Lifting the shade so as to bring the common boundary of gas and air above the beam, the track flashes forth. After the shade is full, if it be inverted, the gas passes upwards like a black smoke among the illuminated particles.

The air of our London rooms is loaded with this organic dust, nor is the country air free from its pollution. However ordinary daylight may permit it to disguise itself, a sufficiently powerful beam causes the air in which the dust is suspended to appear as a semi-solid rather than as a gas. Nobody could, in the first instance, without repugnance place the mouth at the illuminated 
focus of the electric beam and inhale the dirt revealed there. Nor is the disgust abolished by the reflection that, although we do not see the nastiness, we are churning it in our lungs every lour and minute of our lives. There is no respite to this contact with dirt; and the wonder is, not that we should from time to time suffer from its presence, but that so small a portion of it would appear to be deadly to man.

And what is this portion? It was some time ago the current belief that epidemic diseases generally were propagated by a kind of malaria, which consisted of organic matter in a state of motordecay; that when such matter was taken into the body througl the lungs or skin, it had the power of spreading there the destroying process which had attacked itself. Such a spreading power was visibly exerted in the case of yeast. A little leaven was seen to leaven the whole lump, a mere speck of matter in this supposed state of decomposition being apparently competent to propagate indefinitely its own decay. Why should not a bit of rotten malaria work in a similar manner within the human frame? In 1836 a very wonderful reply was given to this question. In that year Cagniard de la Tour discovered the yeast plant, a living organism, which when placed in a proper medium, feeds, grows, and reproduces itself, and in this way carries on the process which we name fermentation. Fermentation was thus proved to be a product of life instead of a process of decay.

Schwann, of Berlin, discovered the yeast plant independently, and in February 1837 he also announced the important result, that when a decoction of meat is effectually screened from ordinary air, and supplied solely with air which has been raised to a high temperature, putrefaction never sets in. Putrefaction, therefore, he affirmed to be carsed by something derived fiom the air, which something could be destroyed by a sufficiently high temperature. The experiments of Schwann were repeated and confirmed by Helmholtz and Ure. But as regards fermentation, the minds of chemists, infuenced probably by the great authority of Gay-Lussac, who ascribed putrefaction to the action of oxygen, fell back upon the old notion of matter in a state of decay. It was not the living yeast plant, but the dead or dying parts of it, which, assailed by oxygen, produced the fermentation. This notion was finally exploded by Pasteur. He proved that the so-called "ferments" are not such; that the true ferments are organised beings which find in the reputed ferments their necessary food.

Side by side with these researches and discoveries, and fortified by them and others, has run the germ theory of epidemic disease. The notion was expressed by Kircher, and favoured by Linnæus, that epidemic diseases are due to germs which float in the atmosphere, enter the body, and produce disturbance by the development within the body of parasitic life. While it was still struggling against great odds, this theory found an expounder and a defender in the President of this Institution. At a time when most of his medical brethren considered it a wild dream, Sir Henry Holland contended that some form of the germ theory was probably true. The strength of this theory consists in the perfect parallelism of the phenomena of contagious disease with those of life. As a planted acorn gives birth to an oak competent to produce a whole crop of acorns, each gifted with the power of reproducing its parent tree, and as thus from a single seedling a whole forest may spring, so these epidemic diseases literally plant their seeds, grow, and shake abroad new germs, which, meeting in the human body their proper food and temperature, finally take possession of whole populations. Thus Asiatic cholera, beginning in a small way in the Delta of the Ganges, contrived in seventeen years to spread itself over nearly the whole habitable world. The development from an infinitesimal speck of the virus of small-pox of a crop of pustules, each charged with the original poison, is another illustration. The reappearance of the scourge, as in the case of the Dreadnought at Greenwich, reported on so ably by Dr. Budd and Mr. Busk, receives a satisfactory explanation from the theory which ascribes it to the lingering of germs about the infected place.

Surgeons have long known the danger of permitting air to enter an open abscess. To prevent its entrance they employ a tube called a cannula, to which is attached a sharp steel point caller a trocar. They puncture with the steel point, and by gentle pressure they force the pus through the cannula. It is necessary to be very careful in cleansing the instrument; and it is difficult to see how it can be cleansed by ordinary methods in air loaded with organic impurities, as we have proved our air to be. The instrument ought, in fact, to be made as hot as its temper will bear. But this is not done, and hence, notwithstanding all the surgeon's care, inflammation often sets in after the first operation, rendering necessary a second and a third. Rapid putrefaction is found to accompany this new inflammation. The pus, moreover, which was sweet at first, and showed no trace of animal life, is now fetid, and swarming with active little organisms called vibrios. Prof. Lister, from whose recent lecture this fact is derived, contends, with every show of reason, that this rapid putrefaction and this astounding development of animal life are due to the entry of germs into the abscess during the first operation, and their subsequent nurture and development under favourable conditions of food and temperature. The celebrated physiologist and physicist Helmholtz is attacked annually by hay-fever. From the 2oth of May to the end of June he suffers from a catarrh of the upper air-passages; and he has found during this period, and at no other, that his nasal secretions are peopled by these vibrios. They appear to nestle by preference in the cavities and recesses of the nose, for a strong sneeze is necessary to dislodge them.

These statements sound uncomfortable; but by disclosing our enemy they enable us to fight him. When he clearly eyes his quarry the eagle's strength is doubled, and his swoop is rendered sure. If the germ theory be proved true, it will give a definiteness to our efforts to stamp out disease which they could not previously possess. And it is only by definite effort under its guidance that its truth or falsehood can be established. It is difficult for an ontsider like myself to read without sympathetic emotion such papers as those of Dr. Budd, of Bristol, on cholera, scarlet-fever, and small-pox. He is a man of strong imagination, and may occasionally take a flight beyond his facts; but without this dynamic heat of heart, the stolid inertia of the free-born Briton cannot be overcome. And as long as the heat is employed to warm up the truth without singeing it over-much; as long as this enthusiasm can overmatch its mistakes by unequivocal examples of success, so long am $I$ disposed to give it a fair field to work in, and to wish it God speed.

But let us return to our dust. It is needless to remark that it cannot be blown away by an ordinary bellows; or, more correctly, the place of the particles blown away is in this case supplied by others ejected from the bellows, so that the track of the beam remains unimpaired. But if the nozzle of a good bellows be filled with cotton wool not too tightly packed, the air urged throngh the wool is filtered of its floating matter, and it then forms a clean band of darkness in the illuminated dust. This was the filter used by Schroeder in his experiments on spontaneous generation, and tumed subsequently to account in the excellent researches of Pasteur. Since 1868 I have constantly employed it myself.

But by far the most interesting and important illustration of this filtering process is furnished by the human breatl. I fill my lungs with ordinary air and breathe through a glass tube across the electric beam. The condensation of the aqueous vapour of the breath is shown by the formation of a luminous white cloud of delicate texture. It is necessary to abolish this cloud, and this may be done by drying the breath previous to its entering into the beam; or still more simply, by warming the glass tube. When this is done the luminous track of the beam is for a time uninterrupted. The breath impresses upon the floating matter a transverse motion, but the dust from the lungs makes good the particles displaced. But after some time an obscure disc appears upon the beam, the darkness of which increases, until finally, towards the end of the expiration, the beam is, as it were, pierced by an intensely black hole, in which no particles whatever can be discerned. The air, in fact, has so lodged its dirt within the lungs as to render the last portions of the expired breath absolutely free from suspended matter. This experiment may be repeated any number of times with the same result. It renders the distribution of the dirt within the lungs as manifest as if the chest were transparent

I now empty my lungs as perfectly as possible, and placing a handful of cotton wool against my mouth and nostrils, inhale through it. There is no difficulty in thas filling the lungs with air. On expiring this air through the glass tube, its freedom from floating matter is at once manifest. From the very beginning of the act of expiration the beam is pierced by a black aperture. The first puff from the lungs abolishes the illuminated dust and puts a patch of darkness in its place, and the darkness continues throughout the entire course of the expiration. When the tube is placed below the beam and moved to and fro, the same 
smoke-like appearance as that obtained with a flame is observed. In short, the cotton wool, when used in sufficient quantity, completely intercepts the floating matter on its way to the lungs.

And here we have revealed to us the true philosophy of a practice followed by medical men, more from instinct than from actual knowledge. In a contagious atmosphere the physician places a handkerchief to his mouth and inhales through it. In doing so he unconsciously holds back the dirt and germs of the air. If the poison were a gas it would not be thus intercepted. On showing this experiment with the cotton wool to Dr. Bence Jones, he immediately repeated it with a silk handkerchief. The result was substantially the same, though, as might be expected, the wool is by far the surest filter. The application of these experiments is obvious. If a physician wishes to hold back from the lungs of his patient, or from his own, the germs by which contagious disease is said to be propagated, he will employ a cotton-wool respirator. After the revelations of this evening such respirators must, I think, come into general use as a defence against contagion. In the crowded dwellings of the London poor, where the isolation of the sick is difficult, if not impossible, the noxious air around the patient may, by this simple means, be restored to practical purity. Thus filtered, attendants may breathe the air unharmed. In all probability the protection of the lungs will be protection of the entire system. For it is exceedingly probable that the germs which lodge in the airpassages, and which, at their leisure, can work their way across the mucous membrane, are those which sow in the body epidemic disease. If this be so, then disease can certainly be warded off by filters of cotton wool. I should be most willing to test their efficacy in my own person. And time will decide whether in lung diseases also the woollen respirator cannot abate irritation, if not arrest decay. By its means, so far as the germs are concerned, the air of the highest Alps may be brought into the chamber of the invalid.

JOHN TYNDALL

\section{SCIENTIFIC SERIALS}

The Zeitschrift für Chemie (No. I) contains an accuunt of some unfinished experiments by Muck on manganous sulphide, and a note by Dr. Baumhauer, of Bonn, on the action of aqueous hydric chloride on nitrobenzol. In the latter of these the author points out the interesting fact that dichloraniline is a principal product of the reaction. Robert Otto communicates several papers containing the results of experiments which he has performed, for the most part, with the co-operation of Eugen Dreher. The subjects of the papers are "Mercuric Diphenyl," under which title a tolerably exhaustive account of this body is given; "Mercuric Ditolyl," which was not so extensively examined; "On the deportment of Dibenzyl at a high temperature" (it splits into Toluol and Toluylene); "On the transformation of hydro-phenylic sulphide into phenylic sulphide" (the mercuric derivative decomposes thus at $180^{\circ}$ :$\left.\left(\mathrm{C}_{6} \mathrm{H}_{5}\right)_{3} \mathrm{H}_{5} \mathrm{~S}_{2}=\left(\mathrm{C}_{6} \mathrm{H}_{5}\right)_{2}, \mathrm{~S}_{2}+\mathrm{H}_{5}\right)$; "On mercuric dinaphtyl," from which it appears that the presence of ethylic acetate is very advantageous in the usual mixture whereby the body is prepared "On mono-ethylic and mono-methylic mercuric acetate;" and "On the preparation of organic sulphur-compounds by means of sodic hyposulphite."-A. Geuther contributes a short article "On the volatile acids of croton oil." He finds that the oil contains no crotonic acid, which name is consequently a misnomer. Of the two metamers, $\mathrm{C}_{4} \mathrm{H}_{6} \mathrm{O}_{2}$, he consequently designates the solid modification tetranylic, and the liquid variely quartenylic acid. Croton oil contains a metamer of angelic acid, for which the author proposes the name tiglinitic acid. - Markownikoff finds that the butylic (fermentation) alcohol, when transformed into iodide, and then, by alcoholic potash, into olefiant, furnishes with hydric iodide the tertiary pseudo-butylic iodide. - Petrieff describes solid azoxytoluide (fusing at $57^{\circ}$ ).

THE Annales de Chimie et de Physique for December last cointains a short note by M. Soliel on an ocular micrometer, the principie of which was discovered independently by Prof. Govi and himself. The rest of the number is wholly occupied by abstracts of foreign scientific papers.

THE Annals and Magazine of Natural History, fourth series, No. 25. The January number of this journal contains the conclusion of Mr. Wollaston's descriptions of the Coleoptera of St. Helena, to which we shall refer elsewhere. Mr. D. Sharp also publishes a paper on the species of Plithydrus found in the Atlaintic Islands, which may be regarded as supplementary to and rectificatory of Mr. Wollaston's works on the Coleoptera of those islands. Dr. Lycett describes a byssiferous fossil Trigonia (T. carniata Ag.) Messrs. A. Hancock and R. Howse describe in considerable detail the remains of a fossil fish (Fanassa bituminosa Schloth.) from the Permian marl-slate of Midderidge in the county of Durham. They identify with the genus Fanassa the coal-measure form described by Messrs. Hancock and Atthey under the name of Climaxodus linguaformis, and regard the genus as belonging to the Rays, and probably allied to Myliobates. The known specimens consist chiefly of the teeth, which were originally described by Schlotheim as Trilobites, under the name of $T$. bituminostus; different examples have been described as fish-remains under various names, and the authors refer to their species the Fanassa angulata,! Humboldti, bitumiroosa, and dictea, Dictea striata and Byzenos latipinnatzes of Count Munster, and the Acroducs larva of Professor Agassiz. This paper is illustrated with two excellent plates. Dr. Carl Semper describes the Helix incequalis (Pfeiff.) from Australia as forming a new genus of Testacellidae, to which he gives thename of Rhytida. Professor E. Perceval Wright describes and figures a new parasitic Crustacean, Pennella orthagorisci, obtained from a sun-fish in Cork Harbour; and Mr. John Gould describes a new Pigeon, Otidiplats nobilis, forming the type of a new genus. - The only botanical paper in the number is the thirty-first instalment of the Rev. W. A. Leighton's "Notulæ Lichenologicæ," containing an analytical examination of certain new characters in the species of the genera Nephromta and Nephro mium.-Besides the translations and abstracts of foreign papers which appear among the miscellaneous contributions, this number contains the first part of a translation of Professor Häckel's memoir on the organisation of sponges, and their relationship to corals, in which the author maintains that the corals (Anthozoa) are very nearly related to the Sponges, that the latter belong to the great group of the Cœlenterata, and that "the sole morphological character which sharply and decidedly separates" them from the rest of the Colenterata is to be found in the "deficiency of the urticating organs in all sponges."

THE Moniteur Scientifique for January ist has much of its space occupied by an account of the legal inquiry resulting from the remarkable explosion of potassic picrate which occurred in the Place de la Sorbonne on the I6th June last. The evidence and the speeches of counsel are given at considerable length. M. Dubrunfant contributes an article on the Saline Analysis of Sugars, and on Melassimetry. There is also the usual account of the sittings of the Academy of Sciences; a Photographic Review, and a review of foreign journals-both very carefully written. A new feature in this serial, introduced this year, is a price-current of the principal products referred to in the papers it contains, and for the general use of subscribers. We cannot, however, help thinking that our able contemporary, in seeking to oblige its readers, has undertaken a task which, from the smailness of available space, it cannot adequately fuifil. A fuil price-current ought to have a periodical to itself.

Revue des Cours Scientifiques, January 22. - The first paper consists of extracts from an eloquent obituary notice of Trousseau, read by M. J. Béchard, the Secretary of the French Academy of Medicine, at the recent annual general meeting. "In this élog" of the man who is one of the most distinguished personifications of the old empirical meclicine, M. Béchard has skilfully contrived to afford us a glimpse of the advent--possibly close at hand-ot scientific medicine." A lecture by M. Lortet on the physiological effects of mountain climbing is the second paper in the present number of the Revuse. We hope shortly to lay before our readers a full accoint of $M$. Lortet's observations. The other papers are one by Prof. Mayer, of Heilbronn, the recently elected Corresponding Member of the Institute of France, on the necessary consequences and inconsequences of the mechanical theory of heat, and a communication, lately presented to the Academy of Sciences, by M. St. Claire Deville, on the nascent state of bodies.

THE American Naturalist.-In the number for the present month there is an original article on the microscopic examination of shavings, and two others on the birds of Massachusetts likewise a continuation of a review of Professor Huxley's Classification of Animals, in which the opinion is expressed that the publication of that book will not endanger the Cuvierian system. A reprint is also given from the Popular Science Review of the temperate and well-written article in which Prof. Cleland, of Glasgow, once more lays the ghost of phrenology, and gives, in a popular way, much solid information. 